\title{
Effects of carotenoids on human immune function
}

\author{
David A. Hughes \\ Diet, Health and Consumer Science Division, Institute of Food Research, Norwich Research Park, Norwich NR4 7UA, UK
}

\begin{abstract}
Many epidemiological studies have shown an association between diets rich in carotenoids and a reduced incidence of many forms of cancer, and it has been suggested that the antioxidant properties of these compounds are a causative factor. Attention has focused on the potential role of one specific carotenoid, $\beta$-carotene, in preventing cancer, and numerous publications have described in vitro experiments and animal studies which suggest that not only can this carotenoid protect against the development of cancer, but also several other chronic diseases. Since the immune system plays a major role in cancer prevention, it has been suggested that $\beta$-carotene may enhance immune cell function. Several human trials, using dietary $\beta$-carotene supplementation with a wide range of intakes, have been undertaken to address this hypothesis. The general conclusion of these studies is that this compound can enhance cell-mediated immune responses, particularly in the elderly. The present article will review some of these human studies and, hopefully, complement the reviews of other authors associated with the present symposium, some of whom will also describe work in this area. Potential mechanisms for the effects of carotenoids on immune function will also be reviewed. Finally, possible reasons for the failure of three major prospective studies to demonstrate a beneficial effect of $\beta$-carotene supplementation on lung cancer risk will be discussed.
\end{abstract}

Carotenoids: Immune function: $\beta$-Carotene: Monocyte

\section{Carotenoids, oxidative stress and cancer}

The carotenoids are a group of over 600 naturally-occurring coloured pigments that are widespread in plants, but of which only about twenty-four commonly occur in human foodstuffs. In nature they serve two essential functions: as accessory pigments in photosynthesis, and in photoprotection. These two functions are achieved through the polyene structure of carotenoids (Fig. 1), which allows the molecules to absorb light and to quench singlet oxygen and free radicals.

The human body is under constant assault from reactive oxygen species, formed as a natural consequence of the body's normal metabolic activity and as part of the immune system's strategy for destroying invading micro-organisms. In addition, the body is exposed to several exogenous sources of free radicals, including ozone, u.v. radiation in sunlight, and cigarette smoke. These unstable molecules can harm the body in many ways, by damaging DNA, denaturing proteins and by causing cell-membrane-lipid peroxidation. Fortunately, the body has developed many defences against this damage, and these defences include both mineral-dependent enzymes (such as Se-dependent
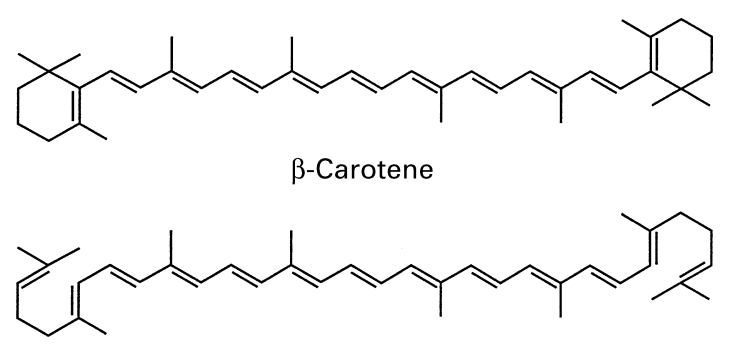

Lycopene<smiles>CC1=CC(O)CC(C)(C)C1/C=C/C(C)=C/C=C/C(C)=C/C=C/C=C(C)/C=C/C=C(C)/C=C/C1=C(C)CC(O)CC1(C)C</smiles>

Lutein<smiles>CC1=C(/C=C/C(C)=C/C=C/C(C)=C/C=C/C=C(C)/C=C/C=C(C)/C=C/C2=C(C)C(O)CC2(C)C)C(C)(C)CCC1</smiles>

Fig. 1. Chemical structure of common dietary carotenoids. 
GSH peroxidase; $E C$ 1.11.1.9) and small molecular antioxidants obtained from the diet, including vitamins $\mathrm{C}$ and $\mathrm{E}$ and the carotenoids. The influence of Se, and of vitamins $\mathrm{C}$ and $\mathrm{E}$ on the human immune system has been reviewed previously (Hughes, 1999).

The immune system is particularly sensitive to oxidative stress. Immune cells rely heavily on cell-cell communication, particularly via membrane-bound receptors, to work effectively. Cell membranes are rich in polyunsaturated fatty acids which, if peroxidized, can lead to a loss of membrane integrity, altered membrane fluidity (Baker \& Meydani, 1994), and aberrant intracellular signalling and cell function. The antioxidant properties of carotenoids are thought to be a causative factor for the close association between diets rich in carotenoids and a reduced incidence of many forms of cancer (Block et al. 1992). In recent years, principally since the review article in Nature by Peto et al. (1981), a great deal of attention has focused on the potential role of one particular carotenoid, $\beta$-carotene (found in high amounts in carrots, broccoli and watercress (Nasturtium officinale)), in preventing cancer. Numerous publications have described in vitro experiments, animal studies and clinical trials that suggest that this carotenoid cannot only protect against cancer, but also cardiovascular disease, stroke, aging, cataract and macular degeneration (for review, see Mayne, 1996). Since the immune system plays a major role in the prevention of cancer, it has been suggested that $\beta$-carotene may enhance immune cell function.

\section{Tests of human immune function in vivo}

One of the few methods of assessing the in vivo effects of a compound on human immune function is to measure the incidence of infection within a group of individuals given either the compound or a placebo. Chandra (1992) compared two groups of elderly volunteers given daily for 1 year either a placebo or a multivitamin supplement containing $16 \mathrm{mg} \beta$-carotene. There was a marked reduction in infection-related morbidity (period of infection; d) in the vitamin-supplemented group, suggesting that the supplement had boosted immune defence in these elderly individuals. However, there have been no comparable studies undertaken examining the effects of individual carotenoids on this measure of immune function. It has to be noted that it would be difficult to undertake similar studies in younger subjects, since they are more likely to have a lower incidence of infection than the elderly, dictating that higher numbers of individuals would be needed to provide sufficient statistical power.

Another means of assessing immune function in vivo is by using the delayed-type hypersensitivity (DTH) response. This procedure gives a measure of the individual's ability to mount a cell-mediated immune response when challenged with a subcutaneous injection of a group of antigens to which they have been previously exposed. The response consists of a $\mathrm{T}$ lymphocyte-mediated local inflammatory reaction which develops over $24-72 \mathrm{~h}$. The response is mediated by inflammatory type- 1 helper T-cells that enter the site of antigen injection, recognize complexes of peptide and major histocompatibility complex (MHC) class II molecules on antigen-presenting cells, and release inflammatory cytokines that increase local blood capillary wall permeability. This results in the influx of fluid and protein into the tissue, producing a characteristic red weal and skin swelling. The lack of a DTH response, particularly in the elderly, is associated with an increased risk of morbidity and mortality (Wayne et al. 1990).

Individuals who are repeatedly exposed to u.v. light show suppression of immune function (Rivers et al. 1989). Since carotenoids can provide photoprotection, several studies have assessed the ability of $\beta$-carotene to protect the immune system from u.v.-induced free radical damage. In one study a group of young males were placed on a lowcarotenoid diet $(<1.0 \mathrm{mg}$ total carotenoids/d) and given either placebo or $30 \mathrm{mg} \beta$-carotene/d for $28 \mathrm{~d}$ before periodic exposure to u.v. light. DTH responses were significantly $(P<0.05)$ suppressed in the placebo group after u.v. treatments, and the suppression was inversely proportional to plasma $\beta$-carotene concentrations in this group (Fuller et al. 1992). No significant suppression of DTH responses were seen in the $\beta$-carotene-treated group. Similar results have also been reported in a more recent study of healthy elderly subjects (Bendich, 1996) who were also supplemented with $30 \mathrm{mg} \beta$-carotene/d or a placebo. However, in this study, although all participants were placed on a low-carotenoid diet, each was supplemented with an additional $1.5 \mathrm{mg} \beta$-carotene/d (the USA average daily intake). Interestingly, the decline in DTH responses in the placebo-treated group was not as significant as that seen in the previous study, suggesting that an intake of $1.5 \mathrm{mg}$ $\beta$-carotene/d may still provide some protection. The ability of $\beta$-carotene to protect against the harmful effects of natural u.v.-sunlight has also been demonstrated (Gollnick et al. 1996) by exposing healthy female students to timeand intensity-controlled sunlight exposure (a Berlin-based study which involved taking volunteers to the Red Sea!).

\section{$\beta$-Carotene and lymphocyte function}

Several studies have examined the effects of $\beta$-carotene on immune function by measuring changes in the numbers of lymphocyte subpopulations and on the expression of cell activation markers. Various doses of $\beta$-carotene have been employed in these studies, ranging from dietary achievable levels of $15 \mathrm{mg} / \mathrm{d}$ up to pharmacological doses of $180 \mathrm{mg} / \mathrm{d}$, provided over periods of 14-365 d.

There have been reported increases in the numbers of T-helper lymphocytes (CD4+) or in CD4+:CD8+ (T-suppressor/cytotoxic cells) T-cells, and in the percentages of lymphocytes expressing the activation markers, interleukin (IL) 2 receptor and transferrin receptor (Alexander et al. 1985; Watson et al. 1991; Murata et al. 1994), particularly in elderly subjects. The potential for increasing the numbers of CD4+ cells led to the suggestion that $\beta$-carotene might be useful as an immunoenhancing agent in the treatment of human immunodeficiency virus (HIV) infection. Preliminary studies have shown a slight but non-significant increase in CD4+ numbers in response to $\beta$-carotene $(60 \mathrm{mg} / \mathrm{d}$ for 4 weeks) in patients with acquired immune deficiency syndrome (Fryburg et al. 1995), but long-term effectiveness has not been reported. However, a recent study of forty-nine HIV-infected subjects, provided 
with vitamin $\mathrm{E}$ and vitamin $\mathrm{C}$, observed a significant $(P<0.01)$ reduction in oxidative stress and a trend towards a reduction in viral load after 3 months (Allard et al. 1998). This study suggests that larger trials of these and other antioxidant nutrients in the treatment of HIV-infected persons are worthwhile, since there is a need to find alternative cheaper treatments than the combination therapies currently employed.

Other investigators have been unable to confirm the increase in T-cell-mediated immunity in healthy individuals following $\beta$-carotene supplementation. Santos et al. (1997) have recently reported the results of two studies in the elderly; a short-term high-dose study $(90 \mathrm{mg} / \mathrm{d}$ for $21 \mathrm{~d})$ in women and a longer-term lower-dose trial $(50 \mathrm{mg}$ on alternate days for 10-12 years) in men. Both studies concluded that there was no significant difference in T-cell function as assessed by DTH response, lymphocyte proliferation, IL-2 and prostaglandin $\mathrm{E}_{2}$ production, and composition of lymphocyte subsets. However, these workers also examined the effect of $\beta$-carotene supplementation on natural killer (NK) cell activity (important for tumour surveillance and eliminating viral infections) in the longerterm trial with male volunteers. Supplementation resulted in significantly $(P<0.05)$ greater NK cell activity compared with subjects of a similar age given placebo treatment (Santos et al. 1996). The study also highlighted the reduction in NK cell activity that is observed with age but, interestingly, the increase in NK cell activity observed in older males (65-86 years) following $\beta$-carotene supplementation restored this activity to the level seen in a group of younger males (51-64 years). Watson et al. (1991) undertook a variable-dose $\beta$-carotene supplementation study $(0,15,30,45$ and $60 \mathrm{mg} / \mathrm{d})$ in small numbers of men and women. They observed an increase in NK cell numbers $(\mathrm{CD} 16+)$ following $\beta$-carotene supplementation of $30-60 \mathrm{mg} / \mathrm{d}$ for 2 months. However, after 2 months cessation of supplementation the values returned to baseline.

\section{$\beta$-Carotene and monocyte function}

Since cell-mediated immune responses are initiated by antigen-presenting cells, we have investigated whether $\beta$-carotene supplementation can influence blood monocytes (the main antigen-presenting cell type in the blood). A prerequisite for antigen-presenting cell function is the expression of MHC class II molecules (human leucocyteassociated antigen (HLA)-DR, HLA-DP and HLA-DQ; Bach, 1985), which are present on the majority of human monocytes. The antigenic peptide is presented to the helper T lymphocyte within a groove of the MHC class II molecule (Fig. 2). Since the degree of immune responsiveness of an individual has been shown to be proportional to both the percentage of MHC class II-positive monocytes and the density of these molecules on the cell surface (Janeway et al. 1984), it is possible that one mechanism by which $\beta$-carotene may enhance cell-mediated immune responses is by enhancing the cell surface expression of these molecules. In addition, cell-to-cell adhesion is critical for the initiation of a primary immune response, and it has been shown that the intercellular adhesion molecule-1 (ICAM-1)-leucocyte function-associated antigen-1 ligand-receptor pair is also

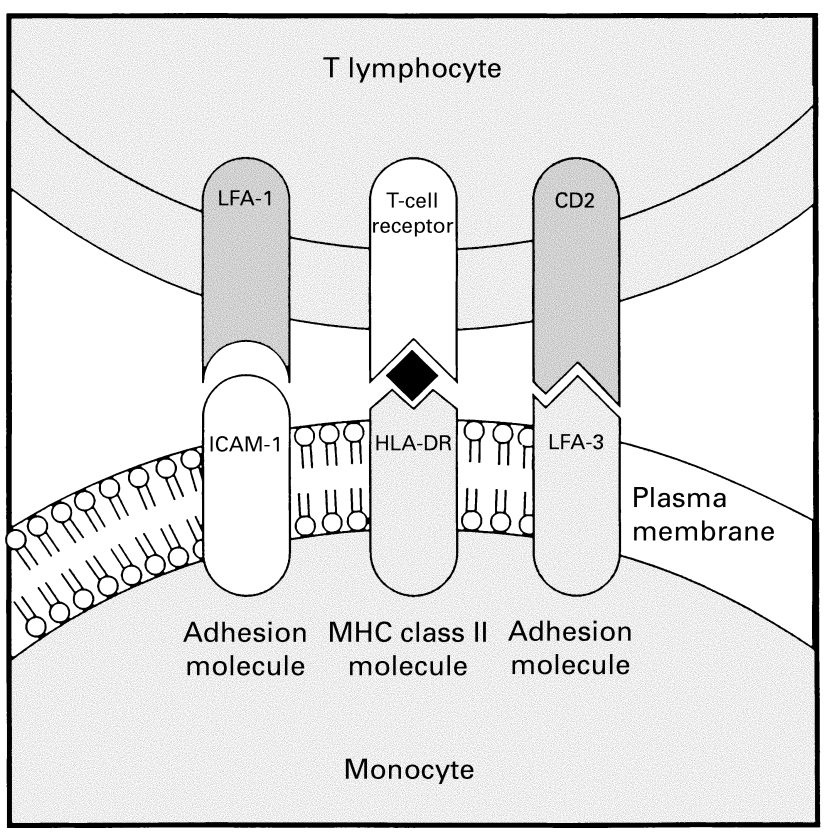

Fig. 2. Cell surface molecules involved in the initiation of cell-mediated immune responses. ( $\bullet$ ), Antigen. LFA, leucocyte function-associated antigen; ICAM-1, intercellular adhesion molecule-1; HLA, human leucocyte-associated antigen; MHC, major histocompatibility complex.

capable of co-stimulating an immune response (Springer, 1990), enhancing T-cell proliferation and cytokine production. Thus, we examined the effect of $\beta$-carotene supplementation at a dietary achievable level $(15 \mathrm{mg} / \mathrm{d}$; equivalent to $150 \mathrm{~g}$ carrots) on the cell surface expression on blood monocytes of MHC class II molecules, and of several adhesion molecules known to be involved in the process of antigen presentation.

We undertook a double-blind placebo-controlled crossover study, in which twenty-five healthy adult male nonsmokers were randomly assigned to receive $\beta$-carotene or placebo for $26 \mathrm{~d}$, followed by the alternative treatment for a further $26 \mathrm{~d}$. Following dietary supplementation there were significant increases $(P<0.05$ in all cases $)$ in plasma levels of $\beta$-carotene and in the percentages of monocytes expressing the MHC class II molecule, HLA-DR, and the adhesion molecules ICAM-1 and leucocyte functionassociated antigen-3 (Hughes et al. 1997a). These results suggest that moderate increases in the dietary intake of $\beta$-carotene can enhance cell-mediated immune responses within a relatively short period of time, providing a potential mechanism for the anti-carcinogenic properties attributed to this compound. The increase in expression of these surface molecules may also, in part, account for the ability of $\beta$-carotene to prevent the reduction in DTH response following exposure to u.v. radiation, since the latter can inhibit both HLA-DR (Khan et al. 1993) and ICAM-1 (Tang \& Udey, 1991) expression on human cell lines. This finding could certainly be relevant to the preventative action of $\beta$-carotene on the formation of skin cancer (Mathews-Roth, 1989), since immunosuppressed individuals, such as renal transplant patients, have an increased risk of skin cancer (Greenwald \& Greenwald, 1983). 
Prabhala et al. (1991), studying the percentage of peripheral-blood mononuclear cells expressing HLA-DR following $\beta$-carotene supplementation at a higher dose of $30 \mathrm{mg} / \mathrm{d}$, did not observe a significant increase in this surface molecule until after 2 months supplementation. However, our study would probably have been more sensitive in detecting changes in the expression of this receptor, since we specifically examined the monocyte population, the major blood cell type expressing MHC class II molecules. Interestingly, these workers also observed a parallel increase in the expression of the activation markers, IL-2 receptor and transferrin receptor, in their mononuclear cell samples, suggesting that the increase in lymphocyte activity is linked to the increased expression of MHC class II molecules on monocytes.

Since so little is known about the influence of other carotenoids on human immune function, we also carried out two further independent studies examining the effect of lycopene (found in tomatoes) and lutein (found in peas, broccoli, spinach (Spinacia oleracea) and other green vegetables), given at the same level of supplementation for the same period of time. Following supplementation with lycopene, an increase in monocyte surface expression of some molecules was observed (HLA-DR, ICAM-1 and leucocyte function-associated antigen-3), but these increases were not as striking as had been seen following supplementation with $\beta$-carotene (Hughes et al. 1997b). One possible explanation for this finding is the low circulating levels of lycopene that were achieved following supplementation. $\beta$-Carotene supplementation resulted in a 5 -fold increase in plasma levels, whereas lycopene levels were increased by only $50 \%$. Whether this difference reflects a lower bioavailability of lycopene compared with $\beta$-carotene, or whether there is a faster excretion, metabolism, or sequestration of this carotenoid to specific sites in the body remains to be established. Supplementation with lutein resulted in a 4-fold increase in plasma lutein levels but, in contrast to $\beta$-carotene, this increase was associated with a decrease in monocyte surface molecule expression (Hughes et al. 1998). Interestingly, other investigators have also shown an opposing effect of $\beta$-carotene and lutein with regard to human lymphocyte proliferation (B Watzl, SL Abrahamse, H Müller, A Bub and G Rechkemmer, unpublished results), emphasizing further the fact that different carotenoids can affect immune function in different ways. Thus, in fruits and vegetables the influence of the combination of the constituent carotenoids on immune function may represent the sum total of these different effects and, indeed, the potential for synergistic effects has not been investigated.

\section{Potential mechanisms of immune modulation}

It is now appreciated that the transcription factor nuclear factor kappa B is required for maximal transcription of many inflammatory cytokines and adhesion molecules, including ICAM-1, and it is thought that the generation of reactive oxygen species is a vital link in mediating nuclear factor kappa B activation by a variety of stimuli (Sen \& Packer, 1996; Jackson et al. 1998). Thus, it is possible that antioxidant nutrients can influence a variety of inflamma- tory processes by inhibiting nuclear factor kappa B activity. This factor might be a possible mechanism for the observed decrease in surface molecule expression on monocytes following supplementation with lutein, but the opposite effect of $\beta$-carotene cannot be explained by this process. One possible factor to explain the different effects seen with different carotenoids might be the preferred location of these compounds within the cell. Carotenoids are lipid soluble, and thus it is thought that most carotenoids will be concentrated in the lipid-rich membranes of the cell. However, their exact location may influence their effectiveness in modulating specific cellular events. To date, very little work has been undertaken to explore the distribution of individual carotenoids within mammalian cells.

An alternative mechanism of immunomodulation is suggested by the particular sensitivity of the immune system to oxidative stress. Peroxidation of the polyunsaturated fatty acids present in cell membranes can lead to a reduction in cell membrane receptor expression (Gruner et al. 1986). In addition, the production of reactive oxygen species by phagocytic immune cells can damage the cells themselves if they are not sufficiently protected by antioxidants. Thus, it is possible that antioxidants such as $\beta$-carotene might prevent oxidative damage to immune cell membranes, enhancing membrane integrity, and elevating the expression of cell surface molecules. It has been demonstrated that free radicals can suppress the expression of the major MHC class II molecule HLA-DR (Gruner et al. 1986), and we have recently shown that dietary supplementation with fish oil, containing $n-3$ polyunsaturated fatty acids which are more vulnerable to lipid peroxidation than are saturated fatty acids, inhibits the expression of HLA-DR and ICAM-1 on human monocytes (Hughes et al. 1996).

Changes in eicosanoid production can also influence the expression of cell membrane molecules. Prostaglandin $E_{2}$ is the major eicosanoid synthesized by monocytes and macrophages, and is known to possess a number of immunosuppressive properties. For example, it can inhibit the expression of Ia molecules (the murine equivalent of human MHC class II molecules) on stimulated macrophages (Snyder et al. 1982). It has been suggested that one mechanism by which $\beta$-carotene might enhance immune responses is by altering the activation of the arachidonic acid cascade (from which prostaglandin $\mathrm{E}_{2}$ is derived), since $\beta$-carotene has been shown to suppress the generation of arachidonic acid products in vitro from non-lymphoid tissues (Halevy \& Sklan, 1987). This possibility requires further investigation.

\section{Prospective studies of $\boldsymbol{\beta}$-carotene supplementation}

In terms of cancer prevention, the strongest epidemiological evidence supports a protective effect of $\beta$-carotene intake in preventing cancer of the lung. Carotenoid intake has been associated with a reduced lung-cancer risk in eight of eight prospective studies and in eighteen of twenty retrospective studies (Zeigler et al. 1996). As a result three major intervention trials were initiated, examining the efficacy of $\beta$-carotene in the prevention of lung cancer (The Alphatocopherol Beta-carotene Cancer Prevention Study Group, 1994; Hennekens et al. 1996; Omenn et al. 1996). The failure of these trials to show a protective effect, with two of 
the studies showing an increase in lung cancer in smokers receiving $\beta$-carotene supplementation, has been widely publicized, although there remains some uncertainty as to whether the increased incidence of lung cancer seen in the Finnish study was restricted to a clinical sub-population of the participants.

The mechanism for the increased lung-cancer risk associated with the supplementation is unclear, but several suggestions have been made. Since the participants in these studies could be classified as 'high-risk' for developing lung cancer (long-term smokers or previously exposed to asbestos), it is possible that many of them had undetected tumours before the commencement of supplementation. The stage (or stages) of carcinogenesis at which $\beta$-carotene might be effective is unclear, but if the effect is mediated via the immune system it is likely to occur during the promotional stages preceding the formation of a malignant tumour.

The worrying possibility is that $\beta$-carotene might actually provide a protective effect to already established tumours. Tumour cells have an impairment in their antioxidant defences compared with normal cells (Toyokuni et al. 1995), and so they might particularly benefit from an increased supply of antioxidants. It has recently been shown that in vitro pre-incubation of tumour cells with various antioxidants, including $\beta$-carotene, can increase their resistance to lysis by NK cells (Riondel et al. 1998). In addition, in our dietary supplementation study we showed that $\beta$-carotene can enhance the production of tumour necrosis factor $\alpha$, a pro-inflammatory cytokine with anti-carcinogenic properties. It has been suggested subsequently that $\beta$-carotene might also increase the production of other mediators such as IL-4 and IL- 6 because of the increased binding of CD4+ $\mathrm{T}$ lymphocytes to MHC class II molecules, which might act as a promoter for existing neoplastic cells present in the lungs of smokers (Fernandes, 1997). However, this author also suggests that moderate $\beta$-carotene supplementation in healthy individuals could elevate tumour necrosis factor $\alpha$ production in a way which might up-regulate equally the MHC class I molecules and increase cytotoxic (CD8+) T and $\mathrm{NK}$ cell function, potentially suppressing further the initiation process of pre-neoplastic cells. This possibility highlights one of the major unresolved problems of $\beta$-carotene; i.e. what intake is required for optimal immune function and other healthy properties. Most studies of this compound have been undertaken at levels which are not achievable within a normal healthy diet. It is still unclear whether different intakes are associated with different outcomes or, in mechanistic studies, with different effects on various aspects of immune function. In addition, there remains the potentiality that, at higher intakes, $\beta$-carotene may exhibit pro-oxidant activity, particularly in the presence of high $\mathrm{O}_{2}$ tensions, as occurs in the lungs (for review, see Palozza, 1998).

\section{Concluding remarks}

There is no doubt that carotenoids, particularly $\beta$-carotene, can influence human immune cell function. However, they may differ in their effects, and the total dietary intake of carotenoids might be critical in determining their overall effect. Further research needs to be undertaken to establish the levels of intake required to optimize immune responsiveness in different groups of the population (e.g. the elderly and smokers) and to examine the interaction between carotenoids and other antioxidant nutrients. In addition, greater emphasis should be placed on studying the effects of enriching the diet with carotenoids via real foodstuffs rather than by supplementation.

\section{Acknowledgements}

The author would like to thank the Biotechnology and Biological Sciences Research Council and the Ministry of Agriculture, Fisheries and Food for financial support.

\section{References}

Alexander M, Newmark H \& Miller G (1985) Oral beta-carotene can increase the number of OKT4 positive cells in human blood. Immunology 9, 221-224.

Allard JP, Aghdassi E, Chau J, Tam C, Kovacs CM, Salit IE \& Walmsley SL (1998) Effects of vitamin E and C supplementation on oxidative stress and viral load in HIV-infected subjects. AIDS 12, 1653-1659.

Bach FH (1985) Class II genes and products of the HLA-D region. Immunology Today 6, 89-94.

Baker KR \& Meydani M (1994) Beta-carotene in immunity and cancer. Journal of Optimal Nutrition 3, 39-50.

Bendich A (1996) Antioxidant vitamins and human immune responses. Vitamins and Hormones 52, 35-62.

Block G, Patterson B \& Subar A (1992) Fruit, vegetables, and cancer prevention: a review of the epidemiological evidence. Nutrition and Cancer 18, 1-29.

Chandra RK (1992) Effect of vitamin and trace-element supplementation on immune responses and infection in elderly subjects. Lancet 340, 1124-1127.

Fernandes G (1997) Beta-carotene supplementation: Friend or foe? Journal of Laboratory and Clinical Medicine 129, 285-287.

Fryburg DA, Mark RJ, Griffith BP, Askenase PW \& Patterson TF (1995) The effect of supplemental beta-carotene on immunological indices in patients with AIDS: a pilot study. Yale Journal of Biological Medicine 68, 19-23.

Fuller CJ, Faulkner H, Bendich A, Parker RS \& Roe DA (1992) Effect of beta-carotene supplementation on photosuppression of delayed-type hypersensitivity in normal young men. American Journal of Clinical Nutrition 56, 684-690.

Gollnick PM, Hopfenmuller W, Hemmes C, Chun SC, Schmid C, Sundermeier K \& Biesalski HK (1996) Systemic beta-carotene plus topical UV-sunscreen are an optimal protection against harmful effects of natural UV-sunlight: results of the BerlinEilath study. European Journal of Dermatology 6, 200-205.

Greenwald ED \& Greenwald ES (1983) Skin cancer. In Cancer Epidemiology, pp. 26-29 [ED Greenwald, editor]. New York: Medical Examination Publishing Co. Inc.

Gruner S, Volk H-D, Falck P \& Baehr RV (1986) The influence of phagocytic stimuli on the expression of HLA-DR antigens; role of reactive oxygen intermediates. European Journal of Immunology 16, 212-215.

Halevy O \& Sklan D (1987) Inhibition of arachidonic acid oxidation by beta-carotene, retinol and $\alpha$-tocopherol. Biochimica et Biophysica Acta 918, 304-307.

Hennekens CH, Buring JE, Manson JE \& Stampfer M (1996) Lack of effect of long term supplementation with beta carotene on the incidence of malignant neoplasms and cardiovascular disease. New England Journal of Medicine 334, 1145-1149. 
Hughes DA (1999) Effects of dietary antioxidants on the immune function of middle-aged adults. Proceedings of the Nutrition Society 58, 79-84.

Hughes DA, Pinder AC, Piper Z, Johnson IT \& Lund EK (1996) Fish oil supplementation inhibits the expression of major histocompatibility complex class II molecules and adhesion molecules on human monocytes. American Journal of Clinical Nutrition 63, 267-272.

Hughes DA, Wright AJA, Finglas PM, Peerless ACJ, Bailey AL, Astley SB, Pinder AC \& Southon S (1997a) The effect of beta-carotene supplementation on the immune function of blood monocytes from healthy male nonsmokers. Journal of Laboratory and Clinical Medicine 129, 309-317.

Hughes DA, Wright AJA, Finglas PM, Peerless ACJ, Bailey AL, Astley SB, Pinder AC \& Southon S (1997b) Comparison of effects of beta-carotene and lycopene supplementation on the expression of functionally associated molecules on human monocytes. Biochemical Society Transactions 25, 206S.

Hughes DA, Wright AJA, Finglas PM, Polley ACJ, Bailey AL, Astley SB, Pinder AC \& Southon S (1998) Effect of lutein supplementation on the expression of functionally associated molecules on human blood monocytes. Immunology 95, Suppl.1, 61.

Jackson MJ, McArdle A \& McArdle F (1998) Antioxidant micronutrients and gene expression. Proceedings of the Nutrition Society 57, 301-305.

Janeway CA, Bottomly K, Babich J, Conrad P, Conzen S, Jones B, Kaye J, Katz M, McVay L, Murphy DB \& Tite J (1984) Quantitative variation in Ia antigen expression plays a central role in immune regulation. Immunology Today 5, 99-104.

Khan IU, Boehm KD \& Elmets CA (1993) Modulation of interferon-gamma-induced HLA-DR expression on the human keratinocyte cell line SCC-13 by ultraviolet radiation. Photochemistry and Photobiology 57, 285-290.

Mathews-Roth MM (1989) Beta-carotene: clinical aspects. In New Protective Roles for Selected Nutrients, pp. 17-38 [GA Spiller and J Scala, editors]. New York: Alan R. Liss Inc.

Mayne SM (1996) Beta-carotene, carotenoids, and disease prevention in humans. FASEB Journal 10, 690-701.

Murata T, Tamai H, Morinobu T, Manago M, Takenaka H, Hayashi K \& Mino M (1994) Effect of long-term administration of betacarotene on lymphocyte subsets in humans. American Journal of Clinical Nutrition 60, 597-602.

Omenn GS, Goodman GE \& Thornquist MD (1996) Effects of a combination of beta carotene and vitamin A on lung cancer and cardiovascular disease. New England Journal of Medicine 334, $1150-1155$.

Palozza P (1998) Prooxidant actions of carotenoids in biological systems. Nutrition Reviews 56, 257-265.
Peto R, Doll R, Buckley JD \& Sporn MB (1981 Can dietary betacarotene materially reduce human cancer rates? Nature $\mathbf{2 9 0}$, 201-208.

Prabhala RH, Garewal HS, Hicks MJ, Sampliner RE \& Watson RR (1991) The effects of 13-cis-retinoic acid and beta-carotene on cellular immunity in humans. Cancer 67, 1556-1560.

Riondel J, Glise D, Fernandez-Carlos T \& Favier A (1998) In vitro comparative study of cytolysis mediated by natural killer cells towards malignant cells preincubated with antioxidants. Anticancer Research 18, 1757-1764.

Rivers JK, Norris PG, Murphy GM, Chu AC, Midgley G, Morris J, Morris RW, Young AR \& Hawk JL (1989) UVA sunbeds: tanning, photoprotection, acute adverse effects and immunological changes. British Journal of Dermatology 120, 767-777.

Santos MS, Leka LS, Ribaya-Mercado JD, Russell RM, Meydani M, Hennekens CH, Gaziano JM \& Meydani SN (1997) Shortand long-term beta-carotene supplementation do not influence T cell-mediated immunity in healthy elderly persons. American Journal of Clinical Nutrition 66, 917-924.

Santos MS, Meydani SN, Leka L, Wu D, Fotouhi N, Meydani M, Hennekens CH \& Gaziano JM (1996) Natural killer cell activity in elderly men is enhanced by beta-carotene supplementation. American Journal of Clinical Nutrition 64, 772-777.

Sen CK \& Packer L (1996) Antioxidant and redox regulation of gene transcription. FASEB Journal 10, 709-720.

Snyder DS, Beller DI \& Unanue ER (1982) Prostaglandins modulate macrophage Ia expression. Nature 299, 163-165.

Springer TA (1990) Adhesion receptors of the immune system. Nature 346, 425-434.

Tang A \& Udey MC (1991) Inhibition of epidermal Langerhans cell function by low dose ultraviolet $B$ radiation. Ultraviolet B radiation selectively modulates ICAM-1 (CD54) expression by murine Langerhans cells. Journal of Immunology 146, 33473355.

The Alpha-tocopherol Beta-carotene Cancer Prevention Study Group (1994) The effect of vitamin E and beta-carotene on the incidence of lung cancer and other cancers in male smokers. New England Journal of Medicine 330, 1029-1035.

Toyokuni S, Okamoto K, Yodoi J \& Hiai H (1995) Persistent oxidative stress in cancer. FEBS Letters 358, 1-3.

Watson RR, Prabhala RH, Plezia PM \& Alberts DS (1991) Effect of beta-carotene on lymphocyte subpopulations in elderly humans: evidence for a dose-response relationship. American Journal of Clinical Nutrition 53, 90-94.

Wayne SJ, Rhyne RL, Garry PJ \& Goodwin JS (1990) Cellmediated immunity as a predictor of morbidity and mortality in subjects over 60. Journal of Gerontology 45, M45-M48.

Zeigler RG, Mayne ST \& Swanson CA (1996) Nutrition and lung cancer. Cancer Causes and Controls 7, 157-177. 